\title{
Encontros e despedidas: migração de mulheres militares da Aeronáutica
}

\author{
Thais Ferreira de Araujo
}

Adriane Roso

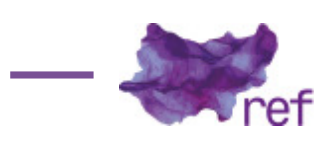

Resumo: Este estudo, de caráter qualitativo, objetivou conhecer os significados das experiências de migração de mulheres no contexto militar. Utilizando um enfoque psicossocial crítico e recorrendo, em especial, às teorias de gênero e a teoria das Representações Sociais, buscou-se, especificamente, compreender de que forma essas experiências contribuíram para a construção da subjetividade. Por meio da narrativa de mulheres militares, concluímos que a experiência de tornar-se uma mulher só, em um lugar desconhecido, está carregada de representações e significados que reforçam permanências em uma cultura de subordinação de gênero, em que as mulheres permanecem em lugares de não poder.

Palavras-chave: mulheres militares; representações sociais; gênero; subjetividade; migrações

Comings and Goings: The Migration of Military Women in the Air Forces

Abstract: This qualitative study aims to identify the meanings attributed to the experience of migration by women in the military context. Using a critical psychosocial approach and particularly gender theories and the theory of social representations, it specifically aims to understand how these experiences contributed to the construction of subjectivities. Through the narration of military women, we concluded that the experience of becoming a woman by herself in an unknown place is full of representations and meanings that reinforce the continuity of a culture of gender subordination, where women remain in powerless positions.

;Keywords: military women; social representations; gender; subjectivity; migration

\section{Introdução: encontros e despedidas}

Encontrar-se e despedir-se representam eventos comuns na vida de muitas pessoas. Há trajetórias de vida, porém, em que esses eventos fazem parte da profissão que escolheram e da vida que sonharam ter. É o caso, por exemplo, de muitos militares brasileiros que passam pela vida encontrando-se e despedindo-se, já que uma das características da vida militar é transferir-se, e assim, migrar para outros lugares.

Quando uma pessoa ingressa em uma instituição militar, uma das lições mais importantes e fundamentais que aprende está descrita em um dos primeiros artigos do Estatuto dos Militares: "O militar deve estar sempre [grifo das autoras] pronto a defender a Pátria, mesmo com sacrifício da própria vida" (BRASIL, 1980). Mais que um regulamento, esta máxima constitui-se em um juramento, realizado solenemente, no momento da incorporação às fileiras das Forças Armadas. Assim, "estar sempre pronto", significa estar sempre disponível, seja qual for a situação, uma vez que tudo o que está em regulamento é regra absoluta e terá que ser cumprido em literalidade. Dentro desse contexto, está previsto também que o militar possa ser movimentado, ou seja, transferido para outro lugar, a qualquer momento, desde que este seja o interesse da instituição, ou para que a "missão seja cumprida", conforme versa o Artigo 176, do Regulamento Interno dos Serviços da Aeronáutica, o RISAER (BRASIL, 1956).

Muitos desses militares são mulheres, cada uma delas trazendo sua história, cada qual com sua motivação que, um dia, a fez decidir pela incorporação às forças armadas, e tornar-se 
militar. Esta não parece ser uma decisão simples, sobretudo para as mulheres, pois se trata de integrar-se a uma instituição de tradição masculina, que demorou a admitir mulheres em suas fileiras, como afirma Emília Takahashi (2002, p. 2). De fato, tornar-se militar, formar-se para a guerra, atirar, combater e voar não costumam ser, comumente, ações identificadas como atribuições de mulheres. Ainda assim, cada vez mais mulheres são incorporadas, todos os anos, às Forças Armadas, este ambiente ainda tão fortemente marcado por oposições de gênero, em que pesa um padrão masculino ao qual as mulheres militares precisariam se adaptar (Cristina Rodrigues da SILVA, 2006; TAKAHASHI, 2002).

Concebemos gênero da mesma forma que Marlene Neves Strey (2012, p. 181-184), ou seja, como um constructo histórico, social e cultural que define significados sobre o que é tornar-se mulher e o que é tornar-se homem. Quando falamos de oposições de gênero no ambiente militar, estamos nos referindo às diferenças que são atribuídas, pela instituição, para homens e mulheres, e que os colocam em posição hierarquicamente desigual. Identificadas como seres frágeis, emotivos, pacificadores e indefesos, pouco sobra de espaço ideológico de valor, para as mulheres, nessa instituição de guerra, que tem como valores essenciais a bravura, a agressividade, a virilidade, valores esses que identificam o "ser homem", em oposição ao "ser mulher" (TAKAHASHI, 2002, p. 1 19-134; Suzana Marly da Costa MAGALHÃES; Ana Lídia de ANDRADE, 2015, p. 140-141).

As mulheres chegam às escolas de formação militar na faixa dos 20 anos, grande parte das vezes, sozinhas, ou seja, sem anteriormente ter conhecido ninguém dos que irão conviver no período de formação. Independentemente da trajetória militar que escolhem, ali irão viver com pessoas diferentes, de diversos lugares do país, e, portanto, com diversas crenças, aptidões e modos de lidar com situações que também são novas. Há que se lidar com os pares, há que se integrar na hierarquia militar, e agir segundo o código de conduta específico para cada nicho desta hierarquia. Há que continuar exercitando a capacidade de ouvir o outro, ceder lugar e, ao mesmo tempo, ocupá-lo, e, paralelamente a tudo isso, tornar-se militar. Na saída da escola militar, novos desafios ainda se impõem: para muitas delas, é hora de se despedir dos colegas de formação e migrar sozinha para um lugar diferente do seu lugar de origem, rumo ao desconhecido. Não é difícil imaginar que, após esse processo de tantas mudanças, de interação com tantas realidades diferentes, novas formas de tornar-se mulher sejam possíveis, novos sujeitos se formem. Cada uma irá (re)significar suas experiências a seu modo, utilizando, para tanto, sua história, sua sensibilidade, suas emoções. No entanto, nada do que é vivido é puramente singular. Como afirma Denise Jodelet (2009, p. 703), toda experiência é construída na coletividade. É por meio da interação social que os saberes se constituem, o que significa que as experiências, apesar de singulares, também são sociais.

Esta perspectiva de sujeito, que é singular e ao mesmo tempo social, foi proposta por Serge Moscovici (2012) ao inaugurar o conceito de Representações Sociais, em 1961 (Clarilza Prado SOUZA; Adelina de Oliveira NOVAES, 2013, p. 21-22). Em um contexto sócio-histórico no qual se acreditava que o conhecimento científico deveria não ser contaminado pelas visões do sujeito, Moscovici buscou ressaltar a importância da interação social e do senso comum para a construção de saberes e significações. Rejeitando as dicotomias tradicionais, entre sujeito e sociedade, utilizou-se da relação entre estes dois elementos para construir um conceito de subjetividade a partir da Teoria das Representações Sociais (MOSCOVICI, 2012; SOUZA; NOVAES, 2013; Fernando Gonzalez REY, 2003).

Angela Arruda (2002, p. 131-133) pontuou que a Teoria das Representações Sociais e as Teorias Feministas trazem características comuns que muito as aproximam: ambas são inovadoras, no sentido de propor novos paradigmas para pensar categorias subvalorizadas (o senso comum e as mulheres); ambas estão ligadas a fenômenos da realidade social; ambas são dinâmicas, flexíveis e se preocupam com a questão da subjetividade. Pensando como Arruda (2002), que as duas teorias muito podem ajudar na compreensão dos fenômenos sociais, neste artigo, também nos utilizamos desta aproximação teórica. Entrelaçando a Teoria das Representações Sociais e as Teorias de Gênero, nos propomos a conhecer os significados das experiências de migração de mulheres no contexto militar da Aeronáutica. Especificamente, buscamos compreender de que forma tais experiências contribuíram para a construção da subjetividade dessas mulheres.

\section{Método}

Diante do exposto, optamos por realizar uma pesquisa de abordagem qualitativa, na área da Psicologia Social. No cenário científico atual, a abordagem qualitativa tem sido bastante utilizada, principalmente quando se deseja conhecer o significado de determinados fenômenos para a vida das pessoas (Egberto Ribeiro TURATO, 2005, p. 510). É por meio dos significados que são atribuídos a um objeto que ele ganha relevância social. Sem conhecê-lo, é possível que todo o objeto/fenômeno se perca, já que se perde o sentido de ele ser e de estar ali (ARRUDA, 2014). Para conhecer os significados e as experiências da migração de mulheres militares, entrevistamos, no período de junho a agosto de 2016, seis mulheres'que integram a Força Aérea Brasileira, na 
Região Sul do Brasil, sendo cada duas delas de círculos hierárquicos distintos, dentro da hierarquia da Aeronáutica², a saber: duas sargentos (Maria e Débora), duas tenentes (Cíntia e Carolina) duas majores (Laura e Joana). As idades das participantes variavam entre 20 e 30 anos nos dois primeiros casos (sargentos e tenentes) e entre 30 e 45 anos no último caso (majores). Nossa escolha apóia-se na perspectiva de Claudia Fonseca (1999), de que uma pesquisa qualitativa é relevante quando todos os seus elementos (sujeitos, objetos, pesquisador) interatuam entre si e estão inseridos em um contexto histórico-social. Busca-se mapear "maneiras de ver e pensar o mundo que não são nem homogêneas, nem estanques. Em outras palavras, nossos modelos sempre vão ser uma simplificação grosseira da realidade" (FONSECA, 1999, p. 76). A análise visa "oferecer uma alternativa, para abrir o leque de interpretações possíveis, não para fechar o assunto ou criar novas fórmulas dogmáticas" (FONSECA, 1999, p. 76). A proposta não é realizar uma generalização abstrata, mas estranhar, esquematizar, desconstruir e comparar os casos para chegar a novas maneiras de compreender, como propõe Fonseca (1999).

Desse modo, julgamos que a quantidade de participantes e a forma pela qual escolhemos nossas entrevistadas foi viável e importante para que fosse possível observar certas nuances entre os relatos, revelando diferenças em relação a alguns aspectos, tais como poder aquisitivo, hierarquia, costumes, formas de viver a vida, etc.

Para a realização das entrevistas, utilizamos uma adaptação da técnica da entrevista narrativa descrita por Sandra Jovchelovitch e Martin Bauer (2013, p. 90-113). Esta técnica é caracterizada como um tipo de entrevista não estruturada, baseada na narração, pela entrevistada, de um determinado evento. Os autores, ao apresentarem a técnica da entrevista narrativa, enfatizam a influência mínima do entrevistador como parâmetro para a sua utilização, bem como uma série de outras regras. Entretanto, entendemos a pesquisa como um processo aberto e de constantes ressignificações, que vai se transformando na medida em que as pessoas, suas histórias e a história que se quer contar vão se cruzando. Para Andreia Vieira Zanella (2013, p. 129-132), fazer pesquisa dessa forma é afirmar o pesquisar como prática social ética, estética e política. Concordamos com a autora e entendemos a necessidade de se reinventar os métodos e as formas de se produzir informações na pesquisa qualitativa.

O uso da entrevista narrativa, ainda que adaptado a este estudo, é justificado pela profundidade que se desejou apreender, dos relatos das mulheres entrevistadas, quando foram convidadas a contar uma história de sua vida. Assim, o ato de narrar sobre determinado fato é capaz de suscitar emoções tanto em quem conta quanto em quem está ouvindo, pois traz à tona experiências e sensações que são reelaboradas por ambos no "aqui" e "agora" (Camila Junqueira MUYLAERT et al., 2014, p. 184-189). Este aspecto, em especial, da entrevista narrativa dá à mesma um caráter colaborativo e interacional, o que vai ao encontro das perspectivas teóricas de base deste estudo.

As entrevistas foram realizadas pela primeira autora da pesquisa, psicóloga, com experiência clínica no contexto militar. A pesquisa, que faz parte do projeto de pesquisa "Saberes, afeto e cultura material: experiências e vozes do consumo na era das conexões" (CAAE 45518415.5 .0000 .5346 - CEP/UFSM) vinculado ao Programa de Pós-Graduação em Psicologia da Universidade Federal de Santa Maria (UFSM), foi autorizada pelo comando local da Aeronáutica, onde foi realizada, e todas as entrevistadas assinaram o Termo de Consentimento Livre e Esclarecido (TCLE), sendo, portanto, voluntárias à participação. Contou-se, também, com a participação de três estudantes de Iniciação Científica que participavam do grupo de pesquisa no qual se insere este trabalho. Elas acompanharam, como observadoras, as entrevistas, contribuindo com a transcrição dos áudios dos encontros e também com a análise das entrevistas, dialogando e compartilhando visões. Esta perspectiva dialógica é tomada por Zanella (2013) ao defender a necessidade do pesquisador, de contextualizar social e historicamente os seus dados. Além disso, consideramos que o diálogo, a interação e o compartilhamento são elementos éticos que trazem coerência e fundamentação a este trabalho. A partir deste momento, conduziremos o leitor a uma espécie de viagem, em que o importante não é tanto o ponto de partida, nem de chegada, mas o processo. Realizaremos este percurso através da letra da música "Encontros e despedidas", de

\footnotetext{
'Grande parte das informações sobre as entrevistadas (nome, idade, cidade de proveniência, etc) foram omitidas ou substituídas por nomes fictícios para garantir seu anonimato e preservar suas identidades, conforme exigência do comandante da unidade militar onde a pesquisa foi realizada.

${ }^{2} O$ ingresso de mulheres na carreira da Aeronáutica se dá, majoritariamente do curso de formação de sargentos, cuja formação, de duração variável para cada especialidade que acontece na Escola de Especialistas da Aeronáutica, localizada na cidade de Guaratinguetá/SP. Dentro do círculo hierárquico dos graduados, obedece-se a seguinte ordem hierárquica: $3^{\circ}$ sargento, $2^{\circ}$ Sargento, $1^{\circ}$ Sargento e suboficial, este último, o topo da carreira de militar graduado. O concurso de nível superior destina-se à incorporação de oficiais aviadoras ou oficiais intendentes. Sua formação acontece na Academia da Força Aérea, localizada em Pirassununga/SP, e tem a duração fixa de quatro anos. O primeiro nível hierárquico da carreira de oficial da Aeronáutica é o de aspirante. Depois, segue-se a seguinte ordem hierárquica: $2^{\circ}$ tenente, $1^{\circ}$ tenente, capitão, major, tenente coronel e coronel. Fonte: //www.fab.mil.br/ ingresso. Acesso em 11/01/2017.
} 
autoria de Milton Nascimento e de Fernando Brandt (1985), que traz uma perspectiva poética à discussão que iremos desenvolver.

\section{"Mande notícias do mundo de lá, diz quem fica. Me dê um abraço, venha me apertar, tô chegando..."}

Estabelecemos, como ponto de partida de nossa análise/viagem, o ingresso na escola de formação militar, quase sempre acompanhado de inúmeras expectativas não só por parte das novas ingressantes, como também dos familiares. Há um mundo desconhecido a ser descoberto, não só no que diz respeito à entrada na vida militar, como também ao início de uma vida independente, autônoma, muitas vezes longe de familiares e amigos. A entrada na instituição militar, dessa forma, é vivida como uma ruptura, acompanhada de sentimentos de medo e estranheza, como expresso na fala de Maria, que incorporou à Aeronáutica como sargento:

Foi no primeiro dia da escola que a ficha foi cair: minha família lá me deixando pra entrar na quarentena... Parecia que era um mundo diferente, sabe? Parecia que eu ia ficar ali naquele mundo, minha família bem longe. Não tinha essa ideia de distância assim, aí, antes eu tava tranquila, até o momento de dar tchau e tudo, daí eu falei "meu Deus, o que que eu tô fazendo?"3

Maria, no final de seu relato, passa a ideia de que talvez não se sentisse autorizada a dar um passo tão grande, sobretudo ao deixar a família. Encontramos, na obra de Simone de Beauvoir, elementos sobre este sentimento de não autorização que é experimentado desde cedo pelas mulheres.

Tratam-na como uma boneca viva e recusam-Ihe a liberdade; fecha-se assim um ciclo vicioso, pois quanto menos exercer sua liberdade para compreender, apreender e descobrir o mundo que a cerca, menos encontrará nele recursos, menos ousará afirmar-se como sujeito. (BEAUVOIR, 2016, p. 25)

De fato, tomando as palavras da autora, eis então um problema peculiar que envolve 0 processo de tornar-se mulher: afirmar-se como sujeito. Problemas mais peculiar ainda para as mulheres militares, uma vez que as bases doutrinárias da instituição militar foram construídas a partir de um "código masculino" (SILVA, 2006, p. 8-9). Logo, como afirmar-se, como construir sua subjetividade neste contexto?

Para Débora, também sargento, tornar-se militar fazia parte de suas aspirações infantis: "eu sempre gostei de carreira militar, né? Desde criança. Quando eu era criança e via aquilo ali... era um sonho". Já para Laura, que incorporou-se às Forças Armadas na carreira de oficial e hoje é major, a entrada na Academia da Força Aérea (AFA) representou uma oportunidade de libertação: "minha mãe, até hoje, é aquela pessoa assim, controladora, preocupada, querendo sempre o melhor pros filhos; e foi um momento de libertação, apesar de eu ir para uma escola militar".

A perspectiva de "libertação", trazida por Laura, ilustra um momento de ruptura, de saída do lugar previamente estabelecido para as mulheres, a esfera privada, o lar. Curioso notar que, para Laura, ir para uma escola militar, uma instituição dura, hierárquica, disciplinar e lá permanecer por quatro anos foi preferível à condição de filha na vida no lar, lugar também repleto de normatizações ligadas ao gênero, como exemplifica Beauvoir:

... ensinam-lhe a cozinhar, a costurar, a cuidar da casa ao mesmo tempo que da toalete, da arte de seduzir, do pudor, vestem-nas com roupas incômodas e preciosas das quais precisam cuidar, penteiam-na de maneira complicada, impõe-lhe regras de comportamento: "Endireite o corpo, não ande como um pata". (BEAUVOIR, 2016, p. 26):

Tal como uma extensão da casa, o quartel também impõe padrões esperados, levando gênero em consideração. A entrada de mulheres na Academia da Força Aérea, em 1996, provocou mudanças nos regulamentos. A partir daquele momento, passava-se a regulamentar o uso de adornos, maquiagens, roupas íntimas, cor e corte de unhas, todos visando à discrição, de forma a neutralizar diferenças físicas entre homens e mulheres, porém, seguindo um padrão de masculinidade (TAKAHASHI, 2002, p. 136-139). Cíntia, de pouco mais de 20 anos, oficial aviadora, destaca que um dos maiores desafios que encontrou ao entrar na AFA foi cortar o cabelo curto, obrigação esta que todas as mulheres precisam seguir ao ingressar. Antes disso, conta que passou por outros desafios na sua chegada à Escola Militar. Nascida em uma cidade de pequeno porte, da região Sul do Brasil, menor de idade, viu-se sozinha pela primeira vez em um dos maiores terminais rodoviários do país, o terminal Rodoviário do Tietê, em São Paulo. Assustou-se, no início,

\footnotetext{
${ }^{3}$ Optamos pelo uso do itálico na fala das entrevistadas, a partir deste ponto do texto, para dar evidência e valorizar as falas de mulheres que, em nossa sociedade, costumam ser silenciadas. As falas das entrevistadas escritas "in natura" reforçam a mensagem que queremos passar, de que as experiências vividas por elas são reais, e não apenas projeções das autoras.
} 
mas conseguiu chegar ao seu destino. Conta também que, ao chegar, teve que se adaptar a morar com cinco pessoas que não conhecia, na escola militar.

Todas as experiências, desafios, adaptações que teve que passar na AFA trouxeram à Cíntia novas formas de ser e estar no mundo, mudanças que identificou em si, que ficaram evidentes quando voltava a sua cidade de origem:

\begin{abstract}
então eu comecei a crescer também, a entender as outras pessoas, enfim a gente vai mudando, vai se adequando ao meio, né? E as pessoas. E isso aconteceu lá também, no primeiro ano, já de cara. Aí eu comparava, tipo, eu aqui, me ralando e as minhas amigas tão lá, festando, fazendo faculdade boa... Aí eu voltava pra casa, saía com elas e via que o papo era outro, sabe? Tô ficando velha, não sei. Já me sentia um pouquinho deslocada, mais madura. Assim, porque elas ainda tavam morando com os pais, ganhavam mesada, e aquele papinho, né? $\mathrm{E}$ eu ...Mas, assim, não criando um clima ruim, mas eu já percebia que tava em mundos diferentes, que eu tava mais a frente, até hoje eu acho assim. Porque eu acho que passei coisas muito diferentes do que elas passaram, cada um tem a sua história, cada um tem a sua vida, né? Mas o que eu já vi de mundo, de mundo não, de Brasil, de vida, muito diferente do que elas viram.
\end{abstract}

Na volta à cidade natal, Cíntia observou que não era mais a mesma depois de sua experiência na Academia Militar. Mas tudo o que passou teve um significado diferente, a partir do contato com as amigas que ficaram. Como afirma Denise Jodelet (2009, p. 692), é a presença do outro, sobretudo a comunicação com este outro, que dá o sentido de tudo o que passamos. É via alteridade que construímos novos sujeitos, uma vez que novos conhecimentos são colocados à disposição, entrando em circulação no espaço público, e construindo representações sociais. Nesse caso, inferimos que também as amigas de Cíntia tornam-se diferentes a partir do contato com as novidades trazidas pela militar que chegou sozinha à rodoviária do Tietê, cortou o cabelo, conviveu com pessoas de diferentes estados, conheceu lugares, sorriu, chorou. Talvez, se nunca mais se encontrassem, não soubessem sobre como funciona a vida militar, e esse saber talvez fizesse bastante diferença, talvez não. Talvez agora quisessem segui-la, ou não segui-la nunca. A este movimento de construção de representações a partir da interação entre os sujeitos, Jodelet (2009, p. 697-698) chamou de intersubjetividade.

O movimento intersubjetivo não pára, sobretudo na vida das mulheres militares, que, ao saírem das escolas de formação militar, são designadas para servirem em cidades diferentes das suas de origem. É chegada a hora de sair da escola, é chegada a hora de mudar mais uma vez, e construir e reconstruir novas representações acerca de si e do outro.

\title{
"Coisa que gosto é poder partir sem ter planos. Melhor ainda é poder voltar quando quero..."
}

Na época em que a entrevista foi realizada, Joana estava na cidade há apenas quatro meses. Anteriormente, servia em sua cidade natal, para a qual foi designada quando saiu da Academia Militar, e lá continuou morando. Conta que, de forma totalmente inesperada, recebeu um comunicado do comando de sua unidade militar que dizia que, por interesse da administração, deveria se mudar para outra unidade militar, em outra cidade. Na ocasião, Ihe foi entregue uma tabela de cidades para onde possivelmente seria transferida, para que pudesse assinalar dentre as alternativas, quais seriam as desejáveis para ela, em ordem de prioridade. A cidade para qual foi designada tinha sido a sua quarta opção na tabela. Escolhida a cidade de destino (não por ela, mas pela administração), teve apenas dois meses para realizar sua mudança.

Na evolução da carreira do oficial militar, estão previstas transferências para outros estados, na medida em que vão se tornando mais antigos na instituição. Joana sabia disso, mas seu relato de como tudo aconteceu revela os efeitos da forma como tal transferência foi por ela recebida:

Os comandos definem quem vai para onde; então, na minha perspectiva, era a época de eu ser movimentada. Então, foi de supetão. Minha vida toda estabilizada na minha cidade.... Estava comprando um imóvel... tinham planos meus que essa notícia meio que me abalou.

Ao falar sobre o abalo sofrido por ocasião de sua transferência, Joana toca na questão de sua saúde, do ponto de vista psicológico, para além das questões práticas a serem resolvidas, em tão pouco tempo, tais como conseguir uma regulamentação de documentos, transferência de carro, etc. Joana precisou mudar radicalmente de vida, e construir, sozinha, novas referências, nova vida, distante de familiares e amigos. Que efeitos, do ponto de vista da saúde das mulheres militares, mudanças assim podem acarretar?

Para Joana, as privações e o rigor da Academia Militar, foram importantes para que, nessa situação, "operacionalmente", pudesse se organizar em tão pouco tempo. Fala esta compartilhada também por todas as oficiais entrevistadas neste estudo. Porém, nesse processo há algo que, conforme ela reconhece, necessita de um pouco mais de tempo para conseguir lidar. Joana fala da saudade dos pais, dos amigos, do sentimento de solidão e de insegurança ao estar sozinha em uma cidade que não reconhece como sendo a sua: 
Talvez eu esteja numa fase da minha vida e da minha carreira que não sei se eu tô realizada ou não. Só que, lá na minha cidade, eu tinha a válvula de escape, eu tinha família, amigos, e então são... começa a vir sentimentos que te angustiam e, não, eu não quero pensar nisso; daí, vai sair, bebe um chope, passeia, aí você vai empurrando com a barriga aquilo que tá te angustiando, até pra você tomar uma atitude. Não sei o que é que eu tenho que fazer pra mudar isso que não tá bom hoje na minha vida. Aqui, em Clareal, eu não tenho a válvula de escape, então o que não tá, o que tá me incomodando, o que hoje eu considero... será que eu fiz uma boa escolha ano passado? Será que... o que eu vou fazer daqui pra frente? Tô feliz? Não tô?

É consenso entre diversos autores que se debruçam sobre a temática da migração de mulheres que os sentimentos envolvidos no ato de migrar podem trazer consequências importantes no que diz respeito à saúde (Joana TOPA et al., 2013; Alcione Leite da SILVA; Maria Teresa DAWSON, 2004; Amalia Conceiro RÚA et al., 2010). Para Silva e Dawson (2004, p. 339-350), dentre os principais problemas de saúde associados à experiência pós-migração, estão a depressão e a ansiedade. Para as imigrantes participantes de suas pesquisas, o sentimento de solidão, surgido, muitas vezes, pela falta de uma rede social e pela sensação de não pertencerem àquela sociedade, contribuíram sobremaneira para o desenvolvimento da depressão e de outras doenças.

Voltando ao caso de Joana, é importante citar que esta ocupa o cargo de major, o que the confere certo status e "empoderamento" dentro da hierarquia militar. Seu estilo de vida remete à noção das chamadas "novas solteiras", ou seja, mulheres que se dizem autônomas, sem filhos, que moram sós, com emprego qualificado e boa remuneração (Eliane GONÇALVES, 201 1, p. 164166). O poder aquisitivo conquistado pelo posto de major, ocupado por Joana, não eliminou por completo as dificuldades, nem fez com que ela não se sentisse só em diversos momentos, assim como não dirimiu suas dúvidas existenciais. Entretanto, sua condição financeira possibilitou, por exemplo, ir com frequência visitar seus familiares, fazendo, talvez, com que essa transição pudesse ser mais suave. Além disso, Joana conseguiu beneficiar-se da nova realidade, na medida em que, morando em uma cidade mais tranquila, de acordo com o seu ponto de vista, aprendeu a desacelerar, no trânsito e na vida. Sua mudança abriu portas para questionar o modo como tem cuidado de si, e para exercer, efetivamente, o autocuidado:

Aí eu pensei: será que eu não tô aqui pra começar a me enxergar; o que eu preciso mudar? Agora eu vou tratar da saúde. Consegui tratar o joelho aqui. Eu vim de um hospital do quarto escalão, e aqui que eu vim tratar meu joelho. Assim, eu dizia: hoje eu vou no ortopedista! Aí, quando eu chegava lá no setor, já tinha um pepino urgente pra resolver, eu deixava a Joana de lado, e não, vamos resolver o problema do hospital... e nisso foi eu fiquei com problema, um ano e meio... Aí eu cheguei aqui, eu disse não, agora eu vou tratar, não só do joelho, eu tô até com problema de dente; é dentário que eu tenho que resolver também e já tô resolvendo.

Como em todos os ambientes, também na Aeronáutica, há mulheres de realidades diversas, há formas diversas de tornar-se mulher e de encarar o processo migratório. Para Débora, por exemplo, a migração parece ter tido outras cores, outras nuances. Vinda de uma cidade de grande porte, ela está na cidade atual desde que se formou sargento, na Escola de Especialistas, há mais de cinco anos. Em relato denso e profundo, contou como a solidão e a saudade da família produziram efeitos que persistem até os dias de hoje:

Eu acho que eu era mais carinhosa. Eu mudei bastante. Eu assumo que até eu, às vezes... um lado é bom. Só que eu não sei se é o lugar... porque eu achei que eu ia me adaptar aqui... eu tentei sair, tentei me adaptar aqui, mas.... eu não acho graça... não acho graça... parece que... é como se tivesse um vazio... No mundo, a gente vai encontrar pessoas boas, como vai encontrar pessoas ruins também. Mas... por eu estar sozinha, aqui, no lugar, eu criei uma raiva do lugar que nada me faz gostar daqui. Nada. Não sei se isso influenciou, por eu ficar sozinha esse tempo todo, né? Pela distância de ver minha família... só que eu não gosto, eu não gosto mesmo do lugar.

O relato da experiência de Débora, em comparação ao de Joana, traz a perspectiva de singularidade do processo migratório, que traz efeitos diferentes para cada uma. É perceptível que o processo de adaptação de Débora apresenta elementos que contribuíram à construção de uma visão sombria da cidade em que hoje mora. Nossas percepções e representações sobre as cidades são também atravessadas por diversos afetos. Não existem representações isoladas, não há neutralidade em representar, em "entender" os lugares, como afirma Arruda (2014, p. 261-268). Cada pessoa, cada mulher irá interpretá-lo conforme suas possibilidades, experiências, atuações no espaço que ocupa.

Débora passou por experiências que a tocaram de forma traumática e que a constituíram da forma como é hoje. Ela conta que se mudou várias vezes desde que chegou, e que o fato de estar longe de seus familiares e amigos a deixou vulnerável a situações de abuso, como aconteceu ao relacionar-se com um colega de trabalho:

E aí foram dois anos assim, ele me maltratando. Me chamava: não, vai ter um churrasco aqui em casa, e vai ser à noite... e eu falei, tá, eu vou sair cedo pra não sair tarde daí... aí ele falava 
"vem" e quando era tarde da noite, ele falava: fica aí que depois eu te levo de carro. E aí eu ficava. E, quando dava meia-noite e pouco, eu falava: "Tem como você me levar? Eu tô com sono", e ele: "Não. Vai a pé. Tu não veio a pé?"| "Tá, mas você falou que ia me levar"| "Eu não vou te levar, tu tem pernas.".

Débora é uma mulher militar, categoria que traz em si uma história de lutas pelo seu reconhecimento como sujeito dentro do quartel (TAKAHASHI, 2002, p. 127-130). Portanto, ela recebeu a mesma formação dada para os homens, com vistas à defesa da pátria, aprendendo atividades consagradas do "universo masculino", tais como manipular uma arma, por exemplo. Tal aprendizado, ainda que desafie padrões esperados para as mulheres, não foi suficiente para que a fizesse sentir-se segura ao sair sozinha à noite, fato que a fez ficar em posição de total dependência do seu amigo. Como afirma Gonçalves (2009, p. 193), não há como falar em democracia e equidade de gênero sem falar também em autonomia, dada também pela liberdade em poder circular aonde quiser, sem que, para isso, tenha que se sentir intimidada.

O medo vivido por mulheres, todos os dias, ao circular pelo espaço público, fundamentase, sobretudo, nas representações em torno da violência contra a mulher. Segundo dados do Fórum Brasileiro de Segurança Pública, foram registrados 47.646 casos de estupro em todo o país em 2014 (FBSP, 2016). Isso significa a média de um estupro a cada 11 minutos. Com isso, não parece difícil inferir que uma mulher não tenha sofrido alguma situação de abuso sexual pelo menos em algum momento de sua vida. Desse modo, para Débora, o fato de voltar a pé, tarde da noite, constitui em si um perigo à sua vida.

Maria havia chegado há pouco tempo na cidade para a qual fora designada, quando passou por uma situação de abuso sexual. Conta que ela e uma amiga tinham sido convidadas para uma festa de inauguração do apartamento de alguns rapazes que tinham vindo junto com elas, da escola de especialistas. Na festa, acabou passando mal, sendo conduzida pela amiga a um quarto da casa para descansar. A amiga havia ficado todo o tempo junto com ela, exceto por um momento, quando saiu para fazer um café. O resto da história segue em detalhes, contada por ela:

Isso nunca tinha acontecido assim, foi a primeira vez que eu fiquei totalmente... né? Aí eu falava assim: você volta, né? Não vai embora. Aí ela: "Fica tranquila, eu vou fazer um café e volto". Mas ela viu que eu tava mal. Ela falou: "Ó, vou trancar a porta, tá?" E ela trancou a porta. Estava tudo escuro. Eu só sei que eu acordo... é meio bizarro isso... eu acordei com ela gritando com um menino, um dos meninos que tinham chegado no meu quarto. Você acredita que ele foi lá, ele morava na casa, ele pegou a chave, abriu e entrou. E ela gritava: "Sai daquil". Ah, eu pulei uma parte. Porque antes, quando estava todo mundo no quarto, ele começou a tentar me beijar, ele viu o jeito que eu tava. Eu lembro de eu falando: "Não!!!". Mas eu não tinha força, sabe? E eu empurrando o rosto dele, só que o que eu achava que eu tava fazendo força, eu não tava fazendo. Foi aí quando a minha amiga falou, saiu todo mundo, expulsou todo mundo e trancou o quarto. Só que ela não imaginava... Ele abriu a porta! Só que eu não lembro se ele fez algo.

A insegurança exemplificada no trecho, pela necessidade da amiga de Maria de trancar o quarto por temer que algo pudesse acontecer (e, de fato, aconteceu) é um dos desdobramentos do que Strey (2012, p. 187) chamou de subordinação de gênero, fenômeno que acontece quando o gênero determina quem tem mais poder. Parafraseando Ana de Miguel e Monserrat Boix (2013, p. 39), na prática, "não vivemos em uma sociedade em que o pertencimento a um determinado gênero - feminino ou masculino - seja irrelevante". As representações que ligam as mulheres à maternidade e ao cuidado da casa são fortes o suficiente para legitimar o confinamento ideológico de mulheres ao espaço privado como sendo natural (STREY, 2012; MIGUEL; BOIX, 2013). Importante salientar que a violência sofrida por Maria teve como agressor um militar, o que sinaliza o quanto a cultura de subordinação de gênero está difundida no ambiente do quartel, transpondo, inclusive, os muros institucionais.

Na instituição militar, diversas práticas discriminatórias de homens em relação às mulheres são legitimadas pelo discurso biológico, que define o corpo da mulher como frágil, destinado à reprodução, e, por isso, não compatível à atividade militar (MAGALHÃES; ANDRADE, 2015, p. 138149). O discurso biológico refere-se à construção subjetiva do "ser mulher" e "ser homem", tecida desde muito cedo por pais, parentes e entretecida também por cada sujeito, no invólucro social que atravessa a vida das pessoas, como afirma Beauvoir (2016), no decorrer de toda a sua célebre obra, O segundo sexo. Tal discurso é disposto, por exemplo, na diferenciação clara entre jogos para meninas e para meninos. Para elas, uma infinidade de bonecas, referências de princesas, casinhas, panelinhas, marcando bem qual seria o seu "lugar social". Para os meninos, destinamse carros, foguetes, aviões, jogos de luta, brinquedos técnicos em geral. Mas - poderíamos dizer já não há mulheres dirigindo todo tipo de veículo e até pilotando aviões? Sim, há. Dentre nossas entrevistadas, há oficiais aviadoras, formadas na Academia da Força Aérea. A primeira turma de aviadoras da Aeronáutica formou-se em 2006. Algumas delas participaram do estudo de Maria 
Miranda Lery Santos e Maria Lucia Rocha Coutinho (2010) sobre a experiência de serem pioneiras em uma carreira até então destinada só para homens, a aviação militar $O$ resultado da pesquisa revelou que as aviadoras veem entraves em conciliar uma possível maternidade com suas carreiras, já que teriam dificuldades para cuidar dos filhos. Tal ideia de responsabilidade pelos cuidados sugere que, apesar do pioneirismo profissional, suas concepções de gênero se enquadram em moldes tradicionais (SANTOS; ROCHA COUTINHO, 2010, p. 262).

A representação social das mulheres enquanto uma categoria voltada para o lar e para a reprodução, e que, por isso, necessita ser protegida e resguardada (GONÇALVES, 2009; STREY, 2012; MIGUEL; BOIX, 2013; BEAUVOIR, 2016), foi identificada em algumas histórias contadas por nossas entrevistadas.

Laura conta que, logo após ter sido transferida para uma grande metrópole, passou por uma situação complicada. Conta que, ao sair do trabalho, seu carro pifou no meio da rua, na pista do meio de uma das ruas mais movimentadas da cidade, e que ponderou: "Se eu tô em casa, primeira coisa: "pai, meu carro pifou". Lá não, não tem pai, é liga pro seguro, e aí, tive que ficar esperando o reboque, uma hora depois, chegar lá". Interessante notar que a figura de auxílio que vêm à cabeça de Laura é o pai (e não a mãe), aquele que, por assim sê-lo, iria resolver o problema do carro e prover a sua segurança.

Em outra situação, Carolina, tenente aviadora, ao cruzar o país de carro por ter sido transferida (foi do Norte ao Sul do país), foi diversas vezes interpelada pelo fato de estar viajando sozinha. Além disso, foi orientada pela mãe, "por motivo de segurança" a viajar com uma "companhia inusitada":

Eu só achei ruim, de solteira, mulher, assim, fazer o translado de carro, porque você vê... que nem eu parava nos postos de gasolina: "Aí, você tá indo pra onde?"/ "Ah, tô indo pra Clareal"./ "Sozinha? Mas não é perigoso?". Daí eu: "É, mas eu vou de qualquer jeito"./ "Não, mas tinha que ter um homem junto contigo, para pelo menos te dar segurança, te defender". E eu: "Tá, mas eu consigo me defender". Daí minha mãe também... minha mãe, ela colocou tipo um ursinho de pelúcia do lado do meu banco, colocou o cinto de segurança e um bonezinho e ela falou: "Ah, pelo menos disfarça. Parece que tem uma pessoa".

O relato do translado de Carolina até o local de destino põe em evidência uma questão apontada por Gonçalves (2009, p. 193) em trabalho sobre as questões que envolvem a vida de mulheres "sós" no Brasil: a noção de que não é seguro - e também não é bem-visto - que uma mulher esteja só. Para a autora, uma mulher que vive só desperta estranhamento e curiosidade, sentimentos que acionam preconceitos e estereótipos ligados à, não aceitação social da solteirice como uma categoria em si, mas como uma preparação para o casamento, como se todas as mulheres tivessem que, obrigatoriamente, se casar. Esta questão encontra respaldo nas mesmas teorias de subordinação de gênero que justificam discriminações e violências, conforme já comentamos. No caso de Carolina, o fato de ser militar e, como disse: "saber se defender", não foi suficiente para que sua mãe deixasse de se preocupar com o fato de ela estar viajando sozinha, mostrando também que a insegurança em circular no espaço público passa de geração em geração, e as mulheres precisam criar estratégias de sobrevivência aos perigos que as concepções e estruturas masculinistas impõem a elas.

As situações descritas nesta seção falam de uma autonomia de ir e vir que, ainda que algumas vezes seja possibilitada pela profissão militar, é relativizada ao esbarrar na questão da (in)segurança. No que diz respeito às mulheres, não se pode, de fato, "partir sem ter planos", ou "voltar quando quero", como diz a música de Milton Nascimento e Fernando Brant (1985), utilizada propositalmente no título desta seção, a fim de demonstrar a forma invisível com a qual a falta de autonomia das mulheres (não) é retratada. Não parece fácil tornar-se mulher e estar só, no espaço público, distante de referências familiares. Há que se buscar outras possibilidades de relações, estas que a própria instituição militar se encarrega de trazer, nos movimentos migratórios.

\section{"Tem gente que chega pra ficar, tem gente que vai pra nunca mais, tem gente que vem e quer voltar, tem gente que val e quer ficar, tem gente a sorrir e a chorar, e assim, chegar e partir"}

Ao escrever sobre formas de se relacionar, que vão além do parentesco, Gonçalves (2009, p. 206) argumenta que as ênfases sociais dadas às relações familiares como fontes inequívocas de amor fazem com que outras relações, como as amizades, por exemplo, não sejam vistas no mesmo patamar de importância. Em seu trabalho, entretanto, percebeu que, embora utilizem uma "ideologia familista" para se expressarem sobre as amizades ("minha família eram meus amigos", "ele é como se fosse meu irmão"), mulheres solteiras (não casadas) as reconhecem como relações mais espontâneas e leves que as relações consanguíneas.

No contexto das militares que migram só, é comum que os vínculos das novas amizades tornem-se tão importantes quanto os de parentesco, já que elas estão fisicamente longe de seus 
familiares. O afeto emanado das relações que surgem no novo lugar faz a diferença na adaptação, no sentimento de pertencimento e na elaboração do novo (ARRUDA, 2014, p. 176-177).

No processo de elaboração da nova realidade, no novo lugar, identificações se aproximam e se afastam, formam novos espaços e intertecem novas representações. Para Susana Seidmann (2015, p. 347-349), a questão identitária está na base do processo de construção de subjetividade, uma vez que o reconhecimento do outro como igual ou como diferente cria e recria a maneira de ser de cada indivíduo, em inter-relação com os outros. Dentre os elementos identificatórios relatados pelas entrevistadas, o mais recorrente foi "a condição de estar só", ou, como dito por elas, "ser solteira também".

Então, assim, foi a minha companheira, porque era solteira, assim como eu, mais ou menos do mesmo jeito assim. A gente não é muito de balada, a gente ia pra happy hours assim, mais cedo, ia sempre no cinema. Então era minha amiga lá; era eu e ela pra lá e pra cá, era sempre a gente (Laura).

E aí, depois, apareceu uma amiga minha... ela era solteira também... a gente começou a andar juntas, e começou a ter aquele laço. E aí foi a minha válvula de escape. Ela tá até hoje, todo o tempo comigo (Débora).

Todavia, o processo de construção subjetiva também é dado pela diferença, é esta que nos diversifica enquanto sujeitos postos em contato com os outros (SEIDMANN, 2015, p. 348). A natureza dos vínculos que as militares fazem parece diferente da observada por Gonçalves (2009, p. 206) quando afirma que "a amizade, enquanto relação voluntariamente escolhida, pode romper mais facilmente as barreiras de classe social". No caso das entrevistadas, foi possível perceber que o pertencimento a círculos hierárquicos distintos (duas sargentos, duas tenentes e duas majores) interfere na formação de vínculos de amizade para fora dos muros do quartel. Considerando que a distância hierárquica também significa distância social, percebemos que as amizades permanecem entre os pares, ainda que haja uma forte representação compartilhada pelos militares da "Família Aeronáutica":

Conheci em termos de trabalho, aprendi muito, conheci muita gente que eu tenho aí, as amizades, até hoje. $E$ assim é bom. Você, às vezes, conhece pessoas que você conhece aqui no trabalho, você liga, tira dúvida; as pessoas: "ah, tudo bom?", "lembra?", então isso ajuda muito no nosso meio aqui (Laura).

Na Aeronáutica, como, no final, todo mundo é uma grande família, vai se contatando, um ajuda o outro, todo mundo tem isso de bom, você sempre vai ter uma referência de alguém em qualquer estado, que tenha organização da Aeronáutica, que eu acho que é um pouco diferente do meio civil... (Joana).

Ao contar sobre a ajuda que teve de outras pessoas ao migrar, Joana fala do caráter "familiar" da Aeronáutica, o que, segundo ela, marca diferenças entre o meio militar e o civil. Há, de fato, entre os militares, uma identidade coletiva formada por todos em torno do ideal de "grande família". De acordo com Silva (2013, p. 863-864), o termo "família militar" possui tanto a dimensão profissional, quando significa o contingente militar, quanto a dimensão privada, quando se refere às famílias (cônjuge, filhos, etc., em um modelo de família nuclear) dos militares. Logo, as duas dimensões juntas formariam a "grande família militar". Como militares, e, portanto, também enquadradas nesse modelo, uma das soluções encontradas pelas entrevistadas para lidar com a solidão foi participar de uma "família emprestada", como aconteceu com Débora:

Fiz amizade quando eu comecei a... eu vivia na casa dessa família. Era um sargento daqui, era ele, a esposa dele e os dois filhos. Eu vivia na casa deles, quase todo fim de semana eu tava lá, dia de semana também. Ele percebeu que eu tava deprimida, e às vezes eu não queria ir pra casa dele, e ele me intimava [para] eu ir pra casa dele. E eu dormia lá... quando eu ficava doente, a esposa dele vinha e cuidava de mim... Eu criei uma ligação tão forte com eles, ao ponto de eu acordar mais cedo quando ele tava viajando pra levar a menina pra escola, e, no fim do expediente, eu pegava o menino. E era assim, toda vez que ele viajava eu sempre fazia isso. E aí ele foi transferido... Eu fiquei... parecia que o meu mundo tinha acabado.

Percebemos que a forma pela qual Débora se insere na família parece acompanhar o padrão da "família militar", uma vez que, claramente, cumpre ali o papel de "filha mais velha". Para Arruda (2014, p. 263), quando nos deparamos com situações novas, torna-se de fato necessário nos ancorarmos em padrões já vividos para que possamos dar sentido às novas experiências. No caso de Débora, é notório que há uma ancoragem na família sócio-afetiva para tornar a experiência da Aeronáutica familiar a ela. A forma como Débora é cuidada pela família relembra o velho (e tão atual) paradigma de fragilidade da mulher, no qual ela precisa ser protegida e resguardada. O significado de autonomia contido no ato de sair de casa para morar sozinha, em um lugar longe da família, contrasta com a necessidade de permanecer em lugares sociais parecidos com os que ocupavam antes de sua saída. Tal situação já foi descrita por Beauvoir (2016, p. 99), ao 
afirmar que "certas moças experimentam mais concretamente a necessidade de um guia, de um senhor. No momento em que escapam do domínio dos pais, sentem-se inteiramente embaraçadas com uma autonomia a que não foram habituadas".

É importante notar que a inserção de Débora na "família emprestada" constrói subjetividades de várias formas, pois a família também se modifica com a sua presença, a partir do momento em que se preocupa, cuida, e lhe atribui responsabilidades. Há ali uma troca clara, um intenso processo intersubjetivo que é permeado pela vivência, pelas crenças a respeito dos lugares designados pelos gêneros, enfim, pelas representações de todos, que são (re) elaboradas na interação entre cada um dos membros. Esta interação é constante, e, considerando o ambiente militar como propício a chegadas e partidas, podemos pensar esse processo intersubjetivo em uma perspectiva potencialmente macro. Ao ser transferida para outro lugar, a família descrita leva consigo outra forma de ser sujeito que, novamente, se modificará, ao entrar em contato com outras famílias, talvez outras "filhas emprestadas", outros lugares, outras crenças. A construção de subjetividades é sempre plástica, multifacetada e surpreendente.

Tornar-se militar da Aeronáutica significa então tornar-se um migrante em potencial, mas significa também ter que lidar com chegadas, partidas, construção e reconstrução de novos vínculos o tempo todo. Carolina, que já foi transferida e também já teve que se despedir de muitos colegas, conta como viveu essa experiência:

É que mudança acaba que afasta, né? A distância afasta. Têm as mídias sociais que você acaba conversando e tal, mas você vê que a amizade acaba se distanciando. Todos os dias eu via muita gente, daí sabia dos problemas, sabia das alegrias, sabia de tudo, convivia com todo mundo. Aí passou os quatro anos, cada turminha foi pra uma parte do Brasil e tem gente que eu não converso desde que eu saí da academia.

Tanto Débora quanto Carolina falam a respeito do processo de afastamento físico dos novos vínculos que fizeram com tristeza e desesperança. Para Carolina, o contato com os amigos através de mídias sociais não substitui o calor da convivência. Em O migrante, seu drama psíquico e a percepção das diferenças, Paula Rebello Oliveira (2005, p. 163-174) escreve sobre o sentimento de "provisoriedade subjetiva" experimentado pelo migrante, que, ao mesmo tempo em que deseja estabelecer-se, também deseja voltar. No caso das mulheres deste estudo, tornar-se migrante também compreende ficar, e ter que lidar com o processo migratório do outro. Para Oliveira (2005, p. 163-174), o migrante, ao inserir-se nesse processo constante de busca por referências tem a necessidade de ressignificar constantemente sua subjetividade. Nessa busca, pode recorrer ao adoecimento como resposta à sua demanda.

Mas a doença não é necessariamente resultado do "ir e vir militar". As participantes, quando perguntadas sobre o que mudou em suas vidas a partir do momento em que começaram a migrar, citam conquistas de diversas naturezas, em sua maioria, ligadas a ideais de autonomia, independência e ao autoconhecimento:

Antes eu pensava assim, que não... que eu era dependente, porque na minha casa era sempre
o meu pai que fazia as coisas, né? Meu pai, minha mãe, então tinha alguém pra fazer. E quando
eu cheguei aqui eu pensei, ah, vou ter que fazer, vou ter que tomar essas decisões que eu
nunca imaginei. Assim... coisas básicas, do tipo: o que eu vou fazer pra comer hoje? A gente
tem que pensar nisso! E eu comecei a ver que dava pra ir seguindo, e eu comecei a viver essa
independência (Maria).

É, você fica mais desapegado à família, né? Você acaba fazendo umas coisas que, às vezes... vamos supor, se você estivesse com o pessoal da sua família seria mais fácil. Mas, sei lá... dificuldade assim, acho que não. Não, assim que eu "ah, não faria mais isso porque foi ruim pra mim", não. Foi mais difícil, mas eu acho que eu faria tudo de novo (Carolina).

(...) então esse isolamento que a cidade me proporcionou me fez enxergar a Joana.. Eu por eu, entendeu? O que é que eu tenho que melhorar; o que que tá errado; qual é meu plano para o futuro (Joana).

O relato das conquistas dessas mulheres, a partir de sua experiência como militares e como migrantes, traz a ideia de que, apesar da forte cultura de subordinação de gênero na qual estão inseridas, há algo nelas que resiste, insiste. Os novos aprendizados, vindos do lugar que ora ocupam no mundo, as transformam em novos sujeitos, com novos repertórios de ações e novas possibilidades. Este movimento as faz refletir sobre o que se tornaram e sobre o que querem ser, as fazendo ressignificar suas escolhas e metas a todo o momento. Transcendendo a perspectiva individual, tal processo se espalha pelas relações que elas estabelecem, pelos vínculos que fazem e desfazem, produzindo também outras formas de ser sujeito em outras pessoas. 


\section{"Conclusão: São só dois lados da mesma viagem: 0 trem que chega é o mesmo trem da partida. A hora do encontro é também de despedida A plataforma dessa estação é a vida desse meu lugar, é a vida!"}

Neste trabalho-viagem, buscamos conhecer os significados da experiência de migração de mulheres no contexto militar, e de que forma estas experiências contribuíram para a construção de sua subjetividade. $\mathrm{O}$ contato com as histórias contadas pelas participantes do estudo nos possibilitou entender, em primeiro lugar, que o processo migratório é intenso, multifacetado e transformador, na medida em que tensiona questões importantes, como o acesso ao espaço público pela mulher, por exemplo. Os relatos que acessamos nos fizeram perceber o quanto a experiência de tornar-se uma mulher só, em um lugar desconhecido, está carregada de representações e significados que reforçam permanências em uma cultura de subordinação de gênero, em que as mulheres permanecem em lugares de não poder. Tornar-se uma mulher militar também apresenta desafios: em uma instituição voltada para a guerra, em que o gênero é considerado segundo paradigmas masculinistas, é preciso resistir para ocupar um lugar de sujeito, sendo mulher.

Nesta viagem que fizemos, passamos tanto por lugares sombrios - histórias de violência, de insegurança, saudade da família, saudade dos vínculos que fazem e se desfazem-, mas também por passagens alegres, trazendo um gosto de vitória, marcadas por momentos de superação de dificuldades. Sabemos que não são apenas mulheres sós que passam pelas angústias de tornaremse mulher e estarem sós no espaço público. Há diversos tipos de solidão ao migrar, inclusive entre mulheres casadas. Entretanto, raros são os estudos que abordam esse tipo de situação, o que aqui nos faz sugerir outras pesquisas nesse sentido, observando, inclusive, as diferenças/ similaridades que concernem a oficiais e graduados, a respeito da migração a cidades de grande e pequeno porte, por exemplo.

Esta pesquisa, ao cruzar universos distintos - das mulheres "sós", da migração e o do universo militar - espera contribuir para adensar os conhecimentos já produzidos sobre tais áreas. Almeja, sobretudo, contribuir com a reflexão crítica em relação à luta das mulheres por equidade, possibilitando a elas, na plataforma dessa estação que é a vida, tornar-se mulher, militar, migrante, ou o que mais quiser ser, em toda a sua plenitude subjetiva. Sugere-se que futuros estudos possam abarcar outras mulheres militares, de diferentes regióes, idade e cargos diferenciados de modo a traçar relações entre eles e possibilitar a elaboração de modelos interpretativos sólidos e consistentes.

\section{Referências}

ARRUDA, Angela. "Brasil Imaginado: representações sociais de jovens universitários". In: SOUZA, Clarilza Prado. de. et al. Angela Arruda e as representações sociais: estudos selecionados. Curitiba: Champagnat, 2014, p. 164-191.

ARRUDA, Angela. "Teoria das representações sociais e teorias de gênero". Cadernos de Pesquisa, São Paulo, v. 117, n. 127, p. 127-147, nov. 2002.

BEAUVOIR, Simone de. O segundo sexo. Volume 2. Rio de Janeiro: Nova Fronteira, 2016.

BRASIL. Decreto $n^{\circ}$ 40.043/1956 de 27 de setembro de 1956. Aprova o Regulamento Interno dos Serviços da Aeronáutica (RISAER). Ministério da Defesa.Rio de Janeiro, 1956.

BRASIL. Lei $n^{\circ}$ 6.880/1980 de 09 de dezembro de 1980. Dispõe sobre o Estatuto dos Militares. Câmara dos Deputados.Brasília, 1980.

FONSECA, Cláudia. "Quando cada caso não é um caso: pesquisa etnográfica e educação". Revista Brasileira de Educação, Rio de Janeiro, n.10, p. 58-78, Jan/Abr. 1999.

FÓRUM BRASILEIRO DE SEGURANÇA PÚBLICA - FBSP. Anuário brasileiro de segurança pública. Ano 10. São Paulo: Fórum Brasileiro de Segurança Pública, 2016.

GONÇALVES, Eliane. "Nem só nem mal acompanhada: reinterpretando a 'solidão' das 'solteiras' na contemporaneidade". Porto Alegre, Horizontes Antropológicos, v. 15, n. 32, p. 189-216, jul/dez. 2009.

GONCALVES, Eliane. Novas solteiras: ecos do feminismo na mídia Brasileira. Cadernos de Pesquisa, São Paulo , v. 41, n. 142, p. 162-187, abr. 2011. 
JODELET, Denise. "O movimento de retorno ao sujeito e a abordagem das representações sociais". Sociedade e estado, Brasília, v. 24, n. 3, p. 679-712, set/dez. 2009.

JOVCHELOVITCH, Sandra., BAUER, Martin.. "Entrevista Narrativa”. In: BAUER, Martin; GASTEL, George. (Orgs.). Pesquisa qualitativa com texto, imagem e som; um manual prático. Petrópolis: Vozes, $\mathrm{p}$. 90-113, 2013.

MAGALHÃES, Suzana Marly da Costa; ANDRADE, Ana Lídia Conceição de. "O corpo feminino, frágil, malsão: um estudo do habitus de gênero dos militares combatentes do Exército Brasileiro". Revista Brasileira de Estudos de Defesa, Porto Alegre, v. 2, n. 1, p.138-153 jan/jun. 2015.

MIGUEL, Ana de; BOIX, Montserrat. "Os gêneros da rede: os ciberfeminismos". In: NATANSOHN, Graciela (Org.). Internet em código feminino. Buenos Aires: La Crujía, 2013, p. 39-75.

MOSCOVICl, Serge. A psicanálise, sua imagem e seu público. Petrópolis: Vozes, 2012.

MUYLAERT, Camila Junqueira et al. "Entrevistas narrativas: um importante recurso em pesquisa qualitativa". Revista da Escola de Enfermagem da USP, São Paulo, v. 48, n. spe2, p. 184-189, 2014.

OLIVEIRA, Paula Rebello "O migrante, seu drama psíquico e a recepção das diferenças". In: PÓVOA NETO, Helion; FERREIRA, Ademir Pacelli (Orgs.). Cruzando fronteiras disciplinares: um panorama dos estudos migratórios. Rio de Janeiro: Revan, 2005.p. 163-174.

REY, Fernando Gonzales. Sujeito e subjetividade: uma apoximação histórico-cultural, São Paulo: Pioneira Thomson Learning, 2003. p. 121-141.

RÚA, Amalia Conceiro, et al. "Satisfación de las necesidades básicas en la población inmigrante femenina Marroquí en Anteixo". Revista da Escola de Enfermagem da USP. São Paulo, v. 44, n.2, p. 249-256, 2010.

SANTOS, Marina Miranda Lery; ROCHA-COUTINHO, Maria Lúcia. "Mulheres na Força Aérea Brasileira: um estudo sobre as primeiras oficiais aviadoras". Estudos de Psicologia, Natal, v. 15, n. 3, p. 259267, set/dez 2010.

SEIDMANN, Susana. "Identidad personal y subjetividad social: educación y constitución subjetiva". Cadernos de Pesquisa, São Paulo, v. 45, n. 156, p. 344-357, abr/jul. 2015.

SILVA, Cristina Rodrigues da. Gênero, Hierarquia e Forças Armadas: um estudo etnográfico acerca da presença de mulheres nos quartéis. São Paulo: UFSCar, 2006.

SILVA, Cristina Rodrigues da. "Famílias de militares: explorando a casa e a caserna no Exército brasileiro". Revista Estudos Feministas, Florianópolis, v. 21, n.3, p. 861-882, set/dez. 2013.

SILVA, Alcione Leite da; DAWSON, Maria Teresa. "The impact of international migration on the health of Brazilian women living in Australia". Texto \& Contexto-Enfermagem, Florianópolis, v. 13, n. 3, p. 339-350, jul/set.2004.

SOUZA, Clarilza Prado; NOVAES, Adelina de Oliveira. "A compreensão de subjetividade na obra de Moscovici". In: ENS, Romilda Teodora; VILLAS BOAS, Lúcia Pintor Santiso; BEHENS Marilda Aparecida (Orgs.). Representações Sociais: fronteiras, interfaces e contextos. São Paulo: Fundação Carlos Chagas, 2013. p. 21-36.

STREY, Marlene Neves et al. Psicologia social contemporânea. Petrópolis: Vozes, 2012.

TAKAHASHI, Emília. Homens e mulheres em campo: um estudo sobre a formação da identidade militar. 2002. Tese (Doutorado em Educação) - Ciências Sociais Aplicadas à Educação, UNICAMP, Campinas, SP, Brasil.

TOPA, Joana et al. Imigração e sáude: a (in)acessibilidade das mulheres imigrantes aos cuidados de saúde. Saúde e Sociedade, São Paulo, v. 22, n. 2, p. 328-341, Abr/Jun 2013.

TURATO, Egberto Ribeiro. "Métodos qualitativos e quantitativos na área da saúde: definições, diferenças e seus objetos de pesquisa". Revista de Saúde Pública, São Paulo, v. 39, n. 3, p. 507514, Jun. 2005.

ZANELLA, Andrea Vieira. Perguntar, registrar, escrever: inquietações metodológicas. Porto Alegre: Sulina, 2013. 
Thais Ferreira de Araujo' (iD) 0000-0002-5248-4401

Mestre em Psicologia pela Universidade Federal de Santa Maria

Thais Ferreira de Araujo é psicóloga formada pela Universidade Federal do Rio de Janeiro. Em fevereiro de 2011 atuou na pesquisa "Perfil dos usuários de crack nas 26 capitais, DF, 9 regiões metropolitanas e Brasil", financiada pela SENAD (Secretaria Nacional de Políticas sobre Drogas) em parceria com a Fiocruz (Fundação Osvaldo Cruz). De março de 2015 a janeiro de 2017 participou como membro integrante do grupo de pesquisa SMIC - Saúde, minorias sociais e comunicação e desenvolveu o projeto de dissertação: Mulheres em Movimento: construções de subjetividades a partir da migração de mulheres militares no Brasil, do qual originou sua dissertação de mestrado, defendida em Janeiro de 2017. Atualmente trabalha como psicóloga clínica especificamente na Base Aérea de Santa Maria, onde atende o efetivo da unidade militar, bem como seus dependentes. Força Aérea Brasileira, Comando da Aeronáutica, Base Aérea de Santa Maria, Subseção de Psicologia do Esquadrão de Saúde da Ala IV

BR-287, KM 240, 8503 - Camobi

97060-500 - Santa Maria - RS - Brasil

(55) 3220-3300

thais.f.a.83@gmail.com

Adriane Rubio Roso (iD) 0000-0001-7471-133X

Pós doutoranda em Psicologia na Harvard University

Adriane Roso é psicóloga, especialista em Saúde Pública e em Gestão em Saúde, doutora em Psicologia, com pós-doutorado em Comunicação com foco em cultura material, práticas socioculturais, representações sociais, tecnologias de comunicação e gênero. Durante os estudos de doutorado, foi bolsista da Fulbright na Columbia University. Professora Associada na Universidade Federal de Santa Maria - UFSM, membro do Grupo de Trabalho 66 Representações Sociais da Associação Nacional de Pesquisa e Pós-Graduação em Psicologia (ANPEPP) (vice-coordenador 2015-2016). Foi pesquisadora do Conselho Nacional de Desenvolvimento Científico e Tecnológico (CNPq) (2015-2018), e desde 2009, vem liderando o Grupo de Pesquisa SMIC cujas áreas de pesquisa são: psicologia social, saúde pública e comunicação. Atualmente, realiza pós-doutorado senior (com Bolsa do CNPq) na Harvard University, no Departamento de Psicologia.

Universidade Federal de Santa Maria (UFSM), Centro de Ciências Sociais e Humanas (CCSH)

Av. Roraima n० 1000, Cidade Universitária - Camobi

97105-900 - Santa Maria - RS - Brasil.

+55 (55) 3220-8000-ccsh@ufsm.br

adrianeroso@gmail.com; adriane.roso@gmail.com

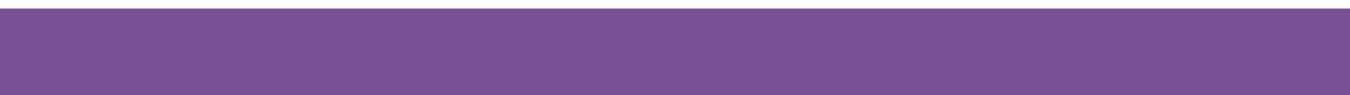

ARAÚJO, Thais Ferreira de; ROSO, Adriane. "Encontros e despedidas: migração de mulheres militares da Aeronáutica". Estudos Feministas, Florianópolis, v. 27, n. 1, (48837), 2019.

\section{CONTRIBUIÇÃO DE AUTORIA}

Thaís Ferreira de Araujo - Concepção. Coleta de dados, Análise de dados, Elaboração do manuscrito, revisão e aprovação da versão final do trabalho

Adriane Rubio Roso - Concepção e elaboração do manuscrito. Coleta de dados Participação ativa da discussão dos resultados; Revisão e aprovação da versão final do trabalho.

\section{FINANCIAMENTO}

Não se aplica

CONSENTIMENTO DE USO DE IMAGEM

Não se aplica 


\section{APROVAÇÃO DE COMITÊ DE ÉTICA EM PESQUISA}

A pesquisa realizada para a escrita deste artigo compõe uma pesquisa maior (projeto guardachuva), intitulado Saberes, afeto e cultura material: experiências e vozes do consumo na era das conexões (registrado sob o n. GAP/CCSH 039397). O projeto guarda-chuva foi aprovado pelo Comitê de Ética em Pesquisa (CEP) da UFSM, sob o CAAE 4551 8415.5.0000.5346 da UFSM.

\section{CONFLITO DE INTERESSES}

Não se aplica

LICENÇA DE USO

Este artigo está licenciado sob a Licença Creative Commons CC-BY. Com essa licença você pode compartilhar, adaptar, criar para qualquer fim, desde que atribua a autoria da obra.

\section{HISTÓRICO}

Recebido em 02/02/2017

Reapresentado em 01/03/2018

Aprovado em 12/06/2018 